\title{
Particle Size Distribution in Aluminum Manufacturing Facilities
}

\author{
Sa Liu ${ }^{1}$, Elizabeth M. Noth ${ }^{1}$, Christine Dixon-Ernst ${ }^{2}$, Ellen A. Eisen ${ }^{1}$, Mark R. Cullen ${ }^{3} \&$ S. Katharine \\ Hammond $^{1}$ \\ ${ }^{1}$ Division of Environmental Health Sciences, School of Public Health, University of California, Berkeley, CA, \\ USA \\ ${ }^{2}$ Alcoa, Pittsburgh, PA, USA \\ ${ }^{3}$ Department of Internal Medicine, Stanford University, Stanford, CA, USA \\ Correspondence: Sa Liu, Division of Environmental Health Sciences, School of Public Health, University of \\ California, Berkeley, 50 University Hall, \#7360, Berkeley, CA 94720-7360, USA. Tel: 1-510-643-0965. E-mail: \\ saliu@berkeley.edu.
}

Received: July 2, 2014 Accepted: July 13, 2014 Online Published: September 24, 2014

doi:10.5539/ep.v3n4p79

URL: http://dx.doi.org/10.5539/ep.v3n4p79

\begin{abstract}
As part of exposure assessment for an ongoing epidemiologic study of heart disease and fine particle exposures in aluminum industry, area particle samples were collected in production facilities to assess instrument reliability and particle size distribution at different process areas. Personal modular impactors (PMI) and Minimicro-orifice uniform deposition impactors (MiniMOUDI) were used. The coefficient of variation (CV) of co-located samples was used to evaluate the reproducibility of the samplers. $\mathrm{PM}_{2.5}$ measured by PMI was compared to $\mathrm{PM}_{2.5}$ calculated from MiniMOUDI data. Mass median aerodynamic diameter (MMAD) and concentrations of sub-micrometer $\left(\mathrm{PM}_{1.0}\right)$ and quasi-ultrafine $\left(\mathrm{PM}_{0.56}\right.$ ) particles were evaluated to characterize particle size distribution. Most of $\mathrm{CVs}$ were less than $30 \%$. The slope of the linear regression of PMI $\mathrm{PM}_{2.5}$ versus MiniMOUDI_PM 2.5 was $1.03 \mathrm{mg} / \mathrm{m}^{3}$ per $\mathrm{mg} / \mathrm{m}^{3}( \pm 0.05)$, with correlation coefficient of $0.97( \pm 0.01)$. Particle size distribution varied substantively in smelters, whereas it was less variable in fabrication units with significantly smaller MMADs (arithmetic mean of MMADs: $2.59 \mu \mathrm{m}$ in smelters vs. $1.31 \mu \mathrm{m}$ in fabrication units, $\mathrm{p}=0.001)$. Although the total particle concentration was more than two times higher in the smelters than in the fabrication units, the fraction of $\mathrm{PM}_{10}$ which was $\mathrm{PM}_{1.0}$ or $\mathrm{PM}_{0.56}$ was significantly lower in the smelters than in the fabrication units $(\mathrm{p}<0.001)$. Consequently, the concentrations of sub-micrometer and quasi-ultrafine particles were similar in these two types of facilities. It would appear, studies evaluating ultrafine particle exposure in aluminum industry should focus on not only the smelters, but also the fabrication facilities.
\end{abstract}

Keywords: particle size distribution, aluminum, smelter, fabrication

\section{Introduction}

Increased risk of cardiovascular disease (CVD) related to particulate matter (PM) in air pollution has become a major public health concern in the US and worldwide. Exposures have been associated with sub-clinical markers of vascular function (Fang et al., 2008; Simkhovich et al., 2008; Fang et al., 2009), hospital admissions (Dominici et al., 2006; Peng et al., 2008) and mortality in both men and women (Dockery et al. 1993, Miller et al. 2007, Ostro et al. 2007). Most attention has focused on fine particles $\left(\mathrm{PM}_{2.5}\right)$, with their ability to penetrate into the alveolar region of the lungs (Laden et al., 2000; Dominici et al., 2006; Ostro et al., 2008; Ostro et al., 2009; Pope et al., 2009). However, evidence regarding occupationally-related heart disease risk associated with PM exposure is scant. One reason for this is historically inadequate characterization of workplace particulate matter such that fine particles $\left(\mathrm{PM}_{2.5}\right)$ have not been regulated separately, hence rarely sampled. As part of an ongoing epidemiologic study evaluating the association between CVD and exposure to $\mathrm{PM}_{2.5}$ in a cohort of approximately 12,000 aluminum workers, we collected extensive personal and area samples in the aluminum production facilities in 2009 - 2010 using both traditional closed-face cassettes (for total particles) and size-specific cascade impactors (for $\mathrm{PM}_{2.5}$ ). Personal samples were used to estimate individual workers exposure to $\mathrm{PM}_{2.5}$ and results were published recently (Noth et al. 2014). Area samples were collected to test instrument performance in the field setting, cross-check the performance of the cascade impactors and explore particle size distributions at different production areas. 
This manuscript reported the results of area samples. Two types of cascade impactors were used, Personal Modular Impactor (PMI) (SKC, Eighty Four, PA), which collects particles in three size factions: $<2.5 \mu \mathrm{m}, 2.5-10$ $\mu \mathrm{m}$, and $>10 \mu \mathrm{m}$, and a six-stage minimicro-orifice uniform deposition impactor (MiniMOUDI)(MSP Corporation, Shoreview, MN) with aerodynamic cut-offs of $0.56 \mu \mathrm{m}, 1.0 \mu \mathrm{m}, 1.8 \mu \mathrm{m}, 3.2 \mu \mathrm{m}, 5.6 \mu \mathrm{m}, 10 \mu \mathrm{m}$ and. The MiniMOUDI provides more detailed information on particle size distribution comparing to the PMI and is able to measure particles in sub-micrometer ranges. However the cost of the MiniMOUDI, along with other factors such as bulkiness and feasibility of being used as a personal sampling device in a work environment, limited its use in personal sample collection in our study. Instead, PMIs were used to collect personal samples side-by-side with cassettes to understand the relationship between $\mathrm{PM}_{2.5}$ and total particles that have been traditionally measured by cassette. In this manuscript we examined the reproducibility of co-located impactor samplers and compared PMI measurements with co-located MiniMOUDI samples to ensure that the PMI provided valid $\mathrm{PM}_{2.5}$ measurements. We also analyzed particle size distributions at different production areas based on MiniMOUDI measurements.

\section{Methods}

\subsection{Sample Collection}

Samples were collected at eight aluminum facilities in 2009 - 2010. These facilities were selected to encompass different manufacturing processes including refining, smelting and fabricating. Sampling locations were determined by a senior industrial hygienist from the company to cover the jobs with the most number of workers or with potential high particle exposures. Because this was an exposure assessment study tailored for the epidemiologic study, the number of replicates at each location and number of locations to be monitored were carefully balanced to serve both the needs of to test instruments and to capture the variations within and between locations. Area samples were collected in triplicate (PMI, MiniMOUDI and cassette) with a sampling board behind the samplers to reduce the influence of current. Duplicate and triplicate samples were collected at a subset of locations to evaluate the precision of the instruments. Samples were collected in each facility under the direction of certified industrial hygienists. Flow rates were 2.0 and 3.0 liters per minute for MiniMOUDI and PMI, respectively, and were checked at the beginning and end of each sampling period. Samples were analyzed gravimetrically according to the National Institute for Occupational Safety and Health (NIOSH) analytical method 0500 (NIOSH 1994) at an American Industrial Hygiene Association accredited industrial hygiene laboratory. Results reported as less than $0.01 \mathrm{mg} / \mathrm{m}^{3}$ for each individual impactor stage (the limit of detection, LD) was assigned a value of $0.007(0.01 / \sqrt{ } 2)$. Some PMI samplers were oiled for the first stage (PM $>10 \mu \mathrm{m}$ stage) to reduce particle bouncing and thus had no results for PM $>10 \mu \mathrm{m}$.

\subsection{Data Analysis}

Coefficient of variation (CV) of co-located samples was used to evaluate the reproducibility of impactor samplers (relative difference was used for duplicate samples). For MiniMOUDI samplers, we used $\mathrm{PM}_{10}$ and $\mathrm{PM}_{3.2}\left(\mathrm{MM}_{-} \mathrm{PM}_{10}\right.$ and $\left.\mathrm{MM}_{-} \mathrm{PM}_{3.2}\right)$ as metrics. For PMI samplers, the reproducibility was evaluated by $\mathrm{PM}_{10}$ and $\mathrm{PM}_{2.5}\left(\mathrm{PMI}_{-} \mathrm{PM}_{10}\right.$ and PMI_PM 2.5$)$. These values are directly measured gravimetrically from individual stages of MiniMOUDI and PMI samplers. PM $_{3.2}$ was chosen as a metric for the MiniMOUDI because it was the stage closest to $\mathrm{PM}_{2.5}$. In order to evaluate the validity of the PMI sampler in measuring PM2.5, we treated the MiniMOUDI as the gold standard (as it measures particles in seven size ranges and gives much detailed particle size distribution information) and compared measured PMI_PM $\mathrm{PM}_{2.5}$ to $\mathrm{PM}_{2.5}$ estimated from MiniMOUDI data $\left(\mathrm{MM}_{-} \mathrm{PM}_{2.5}\right)$. Mass from each MiniMOUDI stage was used to calculate mass fraction of the total mass. The cumulative mass fractions were plotted on a log-probability graph against mid-point of each particle size interval to obtain the particle size distribution; MM_PM 2.5 was calculated from the distribution. Furthermore, the particle distribution on the log-probability plot was used to determine mass median aerodynamic diameter (MMAD, $\mu \mathrm{m})$ and geometric standard deviation (GSD) of the size distribution. MMAD is the particle aerodynamic diameter corresponding to $50 \%$ of cumulative mass, while GSD is determined by the ratio of particle sizes associated with $50 \%$ to $16 \%$ of cumulative mass. We used MMAD and GSD to characterize particle size distributions measured by MiniMOUDI across production areas. Concentrations of $\mathrm{PM}_{1.0}$ (sub-micrometer) and $\mathrm{PM}_{0.56}$ (quasi-ultrafine) particles as measured by MiniMOUDI were also used to compare particle size characteristics across locations.

\section{Results}

A total of 80 PMI and 62 MiniMOUDI samples were collected at 44 production areas/subareas. MiniMOUDI and PMI samplers were co-located at 32 locations. Less than $0.5 \%$ of MiniMOUDI data were below detection limit (particle mass concentration $<0.01 \mathrm{mg} / \mathrm{m}^{3}$ on a stage), whereas about $14 \%$ of PMI data were less than detectable. Particle sizes were approximately lognormally distributed. 


\subsection{Reproducibility of Co-Located Impactors}

Multiple MiniMOUDI samples were collected at 15 locations, with seven duplicates and eight triplicates. Reproducibility was found to be moderate to high for this type of impactor. Precision for MM_PM ${ }_{10}$ appeared to be better than that for MM_PM $\mathrm{PM}_{3.2}$, with only one relative difference for $\mathrm{MM}_{-} \mathrm{PM}_{10}$ above $30 \%$, whereas three relative differences for MM_PM $\mathrm{PM}_{3.2}$ were above 30\% (Figure 1 (a)). Figure 1 (a) also illustrates that all relative differences exceeding $30 \%$ were from samples with either lowest (one sample) or highest (two samples) observed particle concentrations. Twenty sets of concurrent PMI samples were collected, with seven duplicates and thirteen triplicates. PMI samples appeared to be as precise as co-located MiniMOUDI samples (Figure 1 (b)), with one CV for PMI_PM 10 and four CVs (or relative differences) for PMI_PM ${ }_{2.5}$ above $30 \%$. High CVs for PMI_PM 2.5 were all from the samples with low particle concentrations.

Figure 1 Reproducibility of impactors. (a) MiniMOUDI samples, ordered by MiniMOUDI_total; (b) PMI samples, ordered by PMI $\mathrm{PM}_{10}$ as some PMI samples were oiled for the first stage to reduce particle bouncing and thus did not have PMI_total.
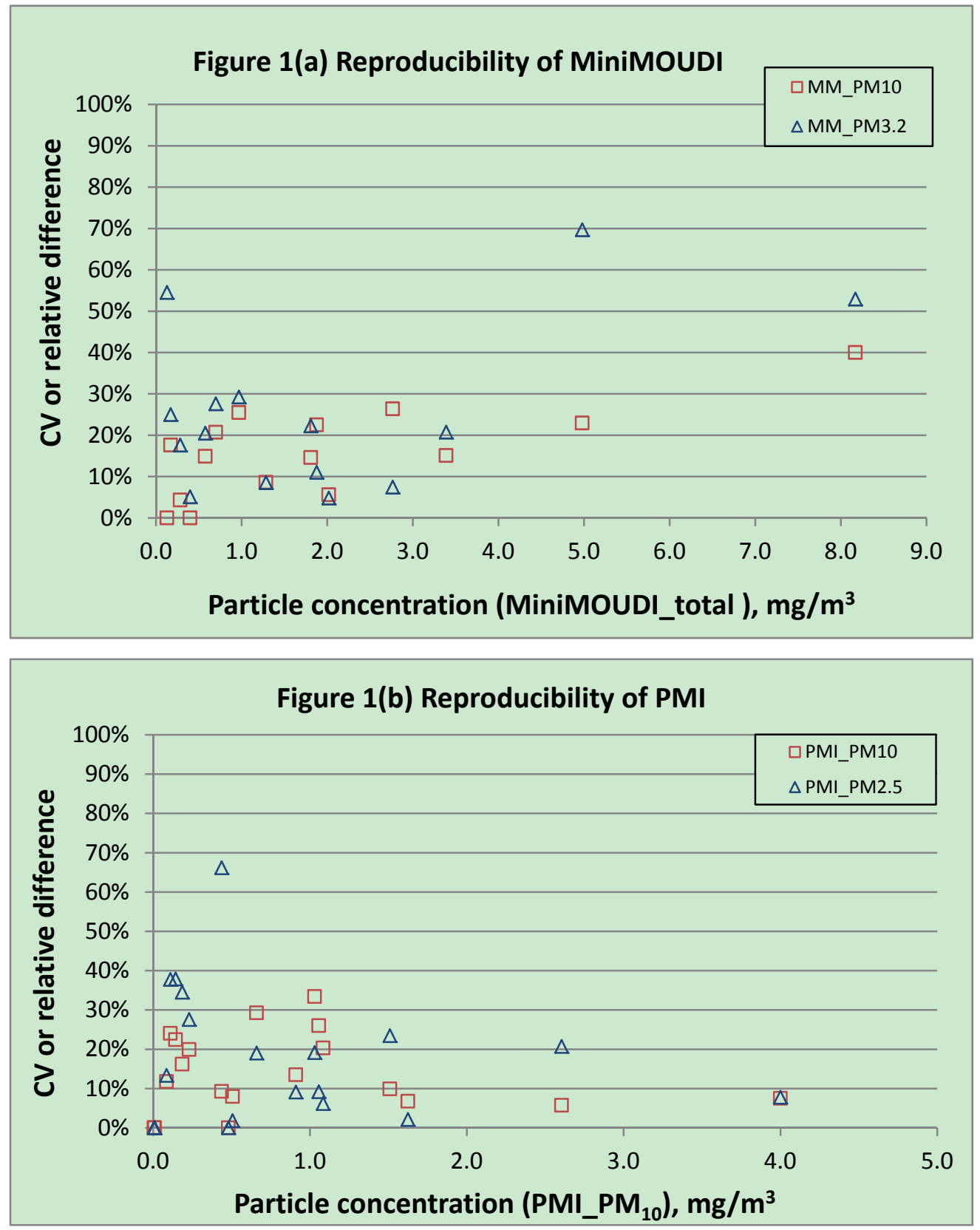

Figure 1. 


\subsection{Comparison of $P M_{2.5}$ between PMI and MiniMOUDI}

PMI and MiniMOUDI samples were collected side-by-side at 32 locations. Figure 2 illustrates the degree of correlation among PMI_PM ${ }_{2.5}$ (measured) and $\mathrm{MM}_{-} \mathrm{PM}_{2.5}$ (calculated). Measured PMI $\mathrm{PM}_{2.5}$ from individual samples ranged from less than $0.01 \mathrm{mg} / \mathrm{m}^{3}$ to $5.9 \mathrm{mg} / \mathrm{m}^{3}$. The slope of the regression line is $1.03( \pm 0.05)$, and the Pearson correlation coefficient $(r)$ is 0.97 ( \pm 0.01$)$; this correlation coefficient drops to 0.71 if two data points with high $\mathrm{PM}_{2.5}$ concentration were omitted.

Figure 2 Correlation between $\mathrm{PM}_{2.5}$ measured by PMI and calculated from MiniMOUDI data. Each data point is an average of co-located samples from same type of samplers. The equations on the upper left corner are the slope and the $\mathrm{R}^{2}$ of the regression line.

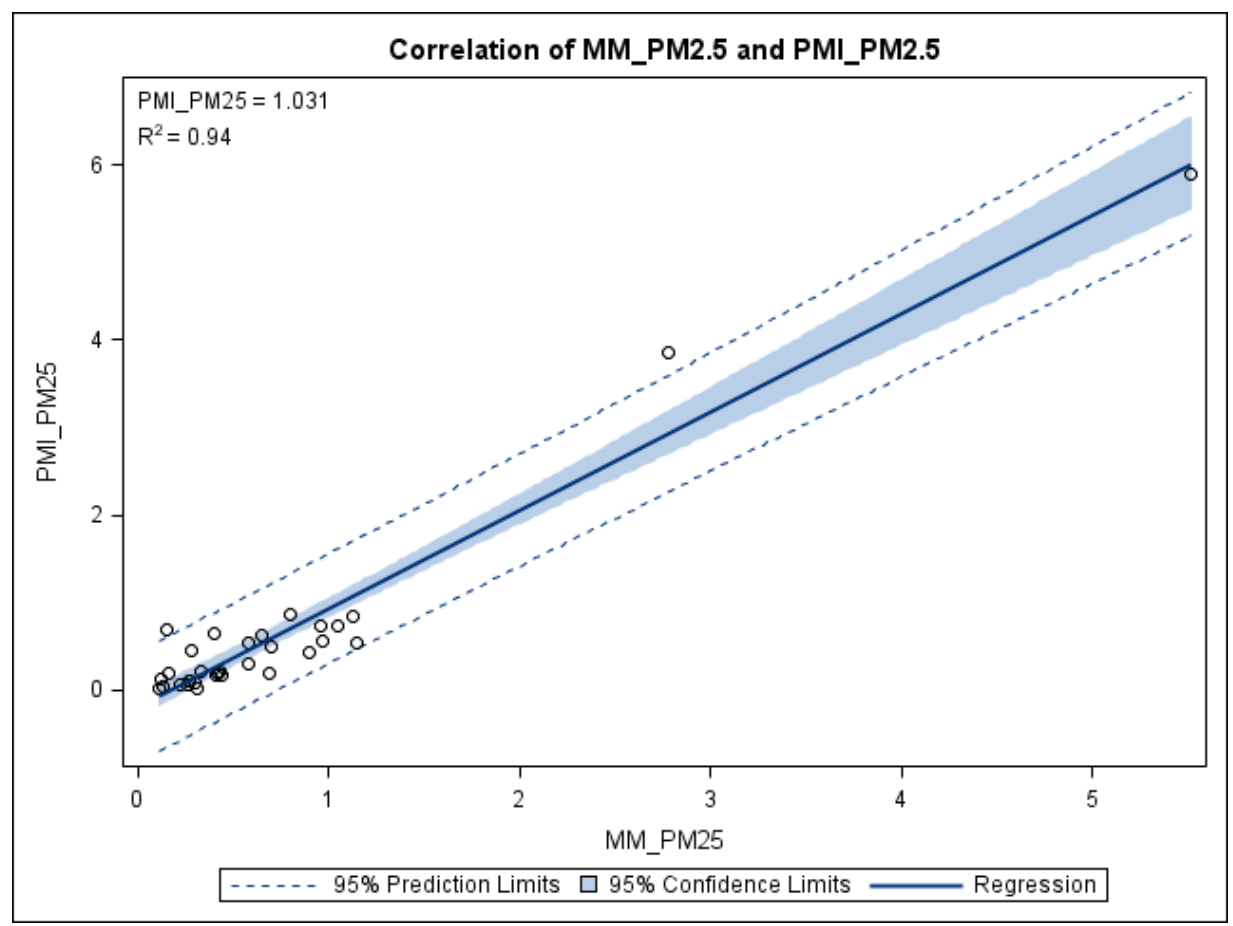

Figure 2 .

\subsection{Particle Size Distribution at Different Production Areas}

We measured particle size distribution by MiniMOUDI at 31 production areas/subareas. The calculated individual MMAD ranged from 0.39 to $6.66 \mu \mathrm{m}$. MMADs from co-located samples were averaged to characterize particle size distribution at each location and reported in Table 1. Our data indicate substantial variations in particle concentration and size distribution across production areas, especially those in smelters. MiniMOUDI_total in smelters ranged from $0.28 \mathrm{mg} / \mathrm{m}^{3}$ to $4.98 \mathrm{mg} / \mathrm{m}^{3}$, with an arithmetic mean (AM) of 1.50 $\mathrm{mg} / \mathrm{m}^{3}$ (Table 1). MMAD varied considerably in smelters (range: $0.68-5.57 \mu \mathrm{m}$, AM: $2.59 \mu \mathrm{m}$ ). Samples collected in the bath crushing area, where raw and recycled material was crushed prior to being mixed with other raw materials (alumina, cryolite) and added to the smelting pots, were characterized by both large particle size and high particle air concentration. In Green Anode where the anode-making process starts, raw material such as calcined coke and binders are blended in heated mixing boxes, and thus large particles and high particle air concentration were observed. However, smaller sized particles were measured in the Baked Anode area, with MMAD less than $1.05 \mu \mathrm{m}$. Particle size and air concentration were similar in potrooms in the two smelters (Facility B and C), suggesting these characteristics may be comparable in potrooms across facilities. 
Table 1. Particle size distribution at different production areas (MiniMOUDI data)

\begin{tabular}{|c|c|c|c|c|c|c|c|c|c|c|c|c|c|c|c|c|c|c|}
\hline \multirow{2}{*}{$\frac{\text { Facility }}{\underline{\text { ID }}}$} & \multirow{2}{*}{$\frac{\text { Facility }}{\text { type }^{\mathrm{a}}}$} & \multirow[t]{2}{*}{$\underline{\text { Department }}$} & \multirow[t]{2}{*}{$\underline{\text { Task/Area }}$} & \multirow[t]{2}{*}{$\underline{\mathrm{n}}$} & \multirow{2}{*}{$\frac{\text { MMAD, }}{\underline{\underline{u m}}}$} & \multirow[t]{2}{*}{$\underline{\text { GSD }}$} & \multicolumn{2}{|c|}{$\underline{\text { MM total }}$} & \multicolumn{2}{|c|}{$\underline{\mathrm{MM} \mathrm{PM}_{10}}$} & \multicolumn{2}{|c|}{$\underline{\mathrm{MM} \mathrm{PM}_{1.0}}$} & \multicolumn{2}{|c|}{$\underline{\mathrm{MM} \mathrm{PM}_{0.56}}$} & \multicolumn{2}{|c|}{$\underline{\mathrm{PM}_{1.0}}{\underline{\mathrm{PM}_{10}}}_{\underline{10}}$} & \multicolumn{2}{|c|}{$\underline{\mathrm{PM}_{0.56}} \underline{\mathrm{PM}_{10}}$} \\
\hline & & & & & & & $\underline{\text { Conc }}^{\mathrm{b}}$ & $\mathrm{CV}^{\mathrm{c}}$ & $\underline{\text { Conc }}^{\mathrm{b}}$ & $\underline{\mathrm{CV}^{\mathrm{c}}}$ & $\underline{\text { Conc }}^{\mathrm{b}}$ & $\underline{\mathrm{CV}^{\mathrm{c}}}$ & $\underline{\text { Conc }}^{\mathrm{b}}$ & $\mathrm{CV}^{\mathrm{c}}$ & $\underline{\text { Ratio }}$ & $\underline{\mathrm{CV}^{\mathrm{c}}}$ & $\underline{\text { Ratio }}$ & $\underline{\mathrm{CV}^{\mathrm{c}}}$ \\
\hline A & $\mathrm{R}$ & EHS & Welding & 3 & 1.3 & 4.1 & 0.58 & $8 \%$ & 0.44 & $15 \%$ & 0.25 & $16 \%$ & 0.17 & $15 \%$ & 0.58 & $1 \%$ & 0.38 & $11 \%$ \\
\hline A & $\mathrm{R}$ & Raw Materials & $\begin{array}{l}\text { General/"A" } \\
\text { Tower Interchange }\end{array}$ & 2 & 5.3 & 2.7 & 8.17 & $38 \%$ & 2.05 & $40 \%$ & 0.37 & $27 \%$ & 0.09 & $67 \%$ & 0.18 & $13 \%$ & 0.05 & $100 \%$ \\
\hline B & $\mathrm{S}$ & Utility Services & $\begin{array}{l}\text { Bath crusher } \\
\text { tending }\end{array}$ & 3 & 2.5 & 2.8 & 1.88 & $17 \%$ & 1.51 & $23 \%$ & 0.23 & $30 \%$ & 0.17 & $31 \%$ & 0.15 & $19 \%$ & 0.11 & $20 \%$ \\
\hline B & S & Potroom & General & 3 & 2.3 & 3.3 & 1.81 & $15 \%$ & 1.23 & $15 \%$ & 0.37 & $22 \%$ & 0.24 & $25 \%$ & 0.30 & $8 \%$ & 0.20 & $11 \%$ \\
\hline B & $\mathrm{S}$ & Potroom & General & 3 & 2.3 & 3.3 & 0.70 & $16 \%$ & 0.49 & $21 \%$ & 0.15 & $35 \%$ & 0.11 & $41 \%$ & 0.30 & $18 \%$ & 0.22 & $27 \%$ \\
\hline B & $\mathrm{S}$ & Potroom & General & 4 & 2 & 3.4 & 0.67 & $25 \%$ & 0.52 & $23 \%$ & 0.15 & $16 \%$ & 0.13 & $14 \%$ & 0.30 & $16 \%$ & 0.25 & $22 \%$ \\
\hline B & $\mathrm{S}$ & Baked Anode & General & 3 & 3.1 & 3.2 & 2.77 & $39 \%$ & 1.60 & $26 \%$ & 0.37 & $8 \%$ & 0.34 & $9 \%$ & 0.24 & $26 \%$ & 0.22 & $27 \%$ \\
\hline $\mathrm{C}$ & $\mathrm{S}$ & $\begin{array}{l}\text { Aluminum } \\
\text { Services }\end{array}$ & $\begin{array}{l}\text { General/ Bath } \\
\text { crusher }\end{array}$ & 2 & 5.6 & 2.6 & 4.98 & $31 \%$ & 3.10 & $23 \%$ & 0.27 & $147 \%$ & 0.24 & $166 \%$ & 0.08 & $136 \%$ & 0.07 & $158 \%$ \\
\hline $\mathrm{C}$ & $\mathrm{S}$ & Potroom & General & 2 & 2.6 & 2.7 & 0.78 & $14 \%$ & 0.65 & $8 \%$ & 0.08 & $0 \%$ & 0.05 & $40 \%$ & 0.12 & $8 \%$ & 0.08 & $33 \%$ \\
\hline $\mathrm{C}$ & $\mathrm{S}$ & Potroom & $\begin{array}{l}\text { General/ } \\
\text { Potroom10, Line5 }\end{array}$ & 2 & 1.9 & 3.5 & 0.97 & $23 \%$ & 0.75 & $26 \%$ & 0.29 & $32 \%$ & 0.17 & $35 \%$ & 0.38 & $6 \%$ & 0.23 & $10 \%$ \\
\hline $\mathrm{C}$ & $\mathrm{S}$ & Potroom & General & 2 & 1.7 & 3.1 & 1.29 & $5 \%$ & 1.05 & $9 \%$ & 0.31 & $16 \%$ & 0.25 & $32 \%$ & 0.29 & $25 \%$ & 0.24 & $40 \%$ \\
\hline $\mathrm{C}$ & $\mathrm{S}$ & Green Anode & $\begin{array}{l}\text { General/ } \\
\text { Greenmill } \\
\text { Running }\end{array}$ & 1 & 5.6 & 2.7 & 2.71 & - & 0.67 & - & 0.11 & - & 0.05 & - & 0.16 & - & 0.07 & - \\
\hline $\mathrm{C}$ & S & Green Anode & General & 1 & 4.2 & 2.6 & 3.03 & - & 1.63 & - & 0.12 & - & 0.06 & - & 0.07 & - & 0.04 & - \\
\hline C & $\mathrm{S}$ & Green Anode & General & 1 & 4.2 & 2.6 & 2.41 & - & 1.23 & - & 0.08 & - & 0.06 & - & 0.07 & - & 0.05 & - \\
\hline $\mathrm{C}$ & $\mathrm{S}$ & Baked Anode & $\begin{array}{l}\text { Bricksaw } \\
\text { operation }\end{array}$ & 3 & 1 & 4.3 & 0.28 & $9 \%$ & 0.23 & $4 \%$ & 0.12 & $8 \%$ & 0.11 & $9 \%$ & 0.52 & $7 \%$ & 0.48 & $8 \%$ \\
\hline $\mathrm{C}$ & S & Baked Anode & General & 1 & 0.9 & 5.3 & 0.38 & - & 0.27 & - & 0.19 & - & 0.18 & - & 0.70 & - & 0.67 & - \\
\hline C & $\mathrm{S}$ & Baked Anode & General & 1 & 0.7 & 4.4 & 0.42 & - & 0.37 & - & 0.19 & - & 0.18 & - & 0.51 & - & 0.49 & - \\
\hline $\mathrm{C}$ & $\mathrm{F}$ & Hot Mill & $\begin{array}{l}\text { General/ } \\
\text { Continuous Mill }\end{array}$ & 1 & 0.9 & 4.4 & 0.84 & - & 0.73 & - & 0.41 & - & 0.34 & - & 0.56 & - & 0.47 & - \\
\hline $\mathrm{C}$ & $\mathrm{F}$ & Hot Mill & $\begin{array}{l}\text { General/ } \\
\text { Reversing Mill }\end{array}$ & 1 & 0.8 & 4.5 & 1.67 & - & 1.54 & - & 0.98 & - & 0.70 & - & 0.64 & - & 0.45 & - \\
\hline & & & Fork Truck & & & & & & & & & & & & & & & \\
\hline $\mathrm{D}$ & $\mathrm{F}$ & Hot Rolling & $\begin{array}{l}\text { Operator/220" } \\
\text { Pulpit }\end{array}$ & 1 & 1.2 & 4.2 & 0.84 & - & 0.62 & - & 0.37 & - & 0.24 & - & 0.60 & - & 0.39 & - \\
\hline $\mathrm{D}$ & $\mathrm{F}$ & Hot Rolling & $\begin{array}{l}\text { Shear } \\
\text { Operation/8"Shear }\end{array}$ & 1 & 1.1 & 4.1 & 0.36 & - & 0.31 & - & 0.16 & - & 0.13 & - & 0.52 & - & 0.42 & - \\
\hline $\mathrm{D}$ & $\mathrm{F}$ & Hot Rolling & $\begin{array}{l}\text { Shear } \\
\text { Operation/3"Shear }\end{array}$ & 1 & 1.6 & 3.9 & 0.47 & - & 0.33 & - & 0.17 & - & 0.10 & - & 0.52 & - & 0.30 & - \\
\hline & & & Cold Mill & & & & & & & & & & & & & & & \\
\hline $\mathrm{D}$ & $\mathrm{F}$ & Cold Rolling & $\begin{array}{l}\text { Operation/816/\#1 } \\
\text { cold Mill Exit }\end{array}$ & 1 & 1.4 & 3.4 & 0.30 & - & 0.27 & - & 0.10 & - & 0.08 & - & 0.37 & - & 0.30 & - \\
\hline $\mathrm{E}$ & $\mathrm{F}$ & Inspection & General & 2 & 1.5 & 3.9 & 0.40 & $10 \%$ & 0.30 & $0 \%$ & 0.14 & $7 \%$ & 0.11 & $10 \%$ & 0.45 & $7 \%$ & 0.35 & $10 \%$ \\
\hline $\mathrm{F}$ & $\mathrm{F}$ & Plate Mill & $\begin{array}{l}\text { Sawing/902W/\#2 } \\
\text { Alu-Cut Saw }\end{array}$ & 2 & 1.8 & 3.4 & 0.64 & $43 \%$ & 0.48 & $33 \%$ & 0.15 & $21 \%$ & 0.13 & $24 \%$ & 0.31 & $13 \%$ & 0.26 & $10 \%$ \\
\hline $\mathrm{F}$ & $\mathrm{F}$ & Ingot Plant & $\begin{array}{l}\text { Ingot } \\
\text { casting/810/4 DC } \\
\text { Pit }\end{array}$ & 1 & 2.3 & 3.1 & 2.14 & - & 1.58 & - & 0.37 & - & 0.22 & - & 0.23 & - & 0.14 & - \\
\hline
\end{tabular}




\begin{tabular}{|c|c|c|c|c|c|c|c|c|c|c|c|c|c|c|c|c|c|c|c|}
\hline G & $\mathrm{F}$ & 101 Metal Cells & $\begin{array}{l}\text { General/ } \\
\text { EQUIAX }\end{array}$ & & 3 & 0.8 & 4.6 & 0.17 & $3 \%$ & 0.15 & $18 \%$ & 0.09 & $38 \%$ & 0.08 & $38 \%$ & 0.59 & $20 \%$ & 0.50 & $19 \%$ \\
\hline $\mathrm{H}$ & $\mathrm{F}$ & Gate Removal & $\begin{array}{l}\text { General/ } \\
10\end{array}$ & PLANT & 1 & 1 & 3.8 & 0.41 & - & 0.35 & - & 0.17 & - & 0.12 & - & 0.49 & - & 0.34 & - \\
\hline $\mathrm{H}$ & $\mathrm{F}$ & Gate Removal & $\begin{array}{l}\text { General/ } \\
10\end{array}$ & PLANT & 1 & 1.7 & 3.2 & . & - & 0.16 & - & 0.06 & - & 0.02 & - & 0.38 & - & 0.13 & - \\
\hline $\mathrm{H}$ & $\mathrm{F}$ & Gate Removal & $\begin{array}{l}\text { General/ } \\
1\end{array}$ & PLANT & 1 & 1.5 & 3.3 & 0.21 & - & 0.18 & - & 0.06 & - & 0.04 & - & 0.33 & - & 0.22 & - \\
\hline $\mathrm{H}$ & $\mathrm{F}$ & Gate Removal & $\begin{array}{l}\text { General/ } \\
1\end{array}$ & PLANT & 2 & 1.3 & 3.7 & 0.13 & $15 \%$ & 0.12 & $0 \%$ & 0.07 & $86 \%$ & 0.05 & $120 \%$ & 0.58 & $86 \%$ & 0.42 & $120 \%$ \\
\hline
\end{tabular}

${ }^{\mathrm{a}}$ Facility type, $\mathrm{R}$ = refinery; $\mathrm{S}=$ smelter; $\mathrm{F}$ = fabrication.

${ }^{\mathrm{b}}$ Particle air concentration, in $\mathrm{mg} / \mathrm{m}^{3}$.

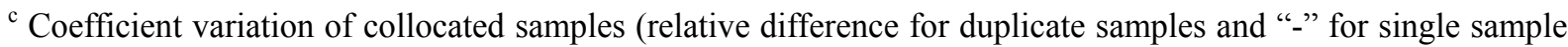
at a location).

In contrast, both particle size and concentration were much less variable in the fabrication units than in the smelters. Particle size was significantly smaller in fabrication units than smelters $(p=0.001)$, with AM of MMAD equal to 1.31 (range: $0.39-2.27 \mu \mathrm{m}$ ). MMADs within the same department were similar at different locations or for different tasks. MiniMOUDI_total did not vary substantially in fabrication units, almost always less than $1.0 \mathrm{mg} / \mathrm{m}^{3}$ except at two locations (Table 1). Although total particle concentration was significantly higher in smelters than in the fabrication units $\left(A M=1.50 \mathrm{mg} / \mathrm{m}^{3}\right.$ vs. $\left.0.69 \mathrm{mg} / \mathrm{m}^{3}, \mathrm{p}<0.05\right)$, the difference in concentrations diminished in sub-micrometer and quasi-ultrafine particle size ranges (Figure 3 ) because particles in fabrication units were predominantly small and the fraction of $\mathrm{PM}_{10}$ which was $\mathrm{PM}_{1.0}$ or $\mathrm{PM}_{0.56}$ was significantly higher in the fabrication units than in smelters $(\mathrm{p}<0.001)$ (Table 1$)$.

Figure 3 Box and whiskers plots showing particle concentrations $\left(\mathrm{mg} / \mathrm{m}^{3}\right)$ by particle size and facility type (smelter vs. fabrication), as measured by MiniMOUDI. (a) total particles (MM_total); (b) Submicrometer particles $\left(\mathrm{PM}_{1.0}\right.$ and quasi-ultrafine particles). Boxes extend from the 25 th to the 75 th percentile, horizontal bars inside the boxes represent the median, diamonds inside the boxes represent the mean, whiskers extend to maximum and minimum observations within 1.5 times the length of the intra-quartile range (IQR) above and below the 75th and 25th percentiles, respectively, and outliers are represented as circles. 

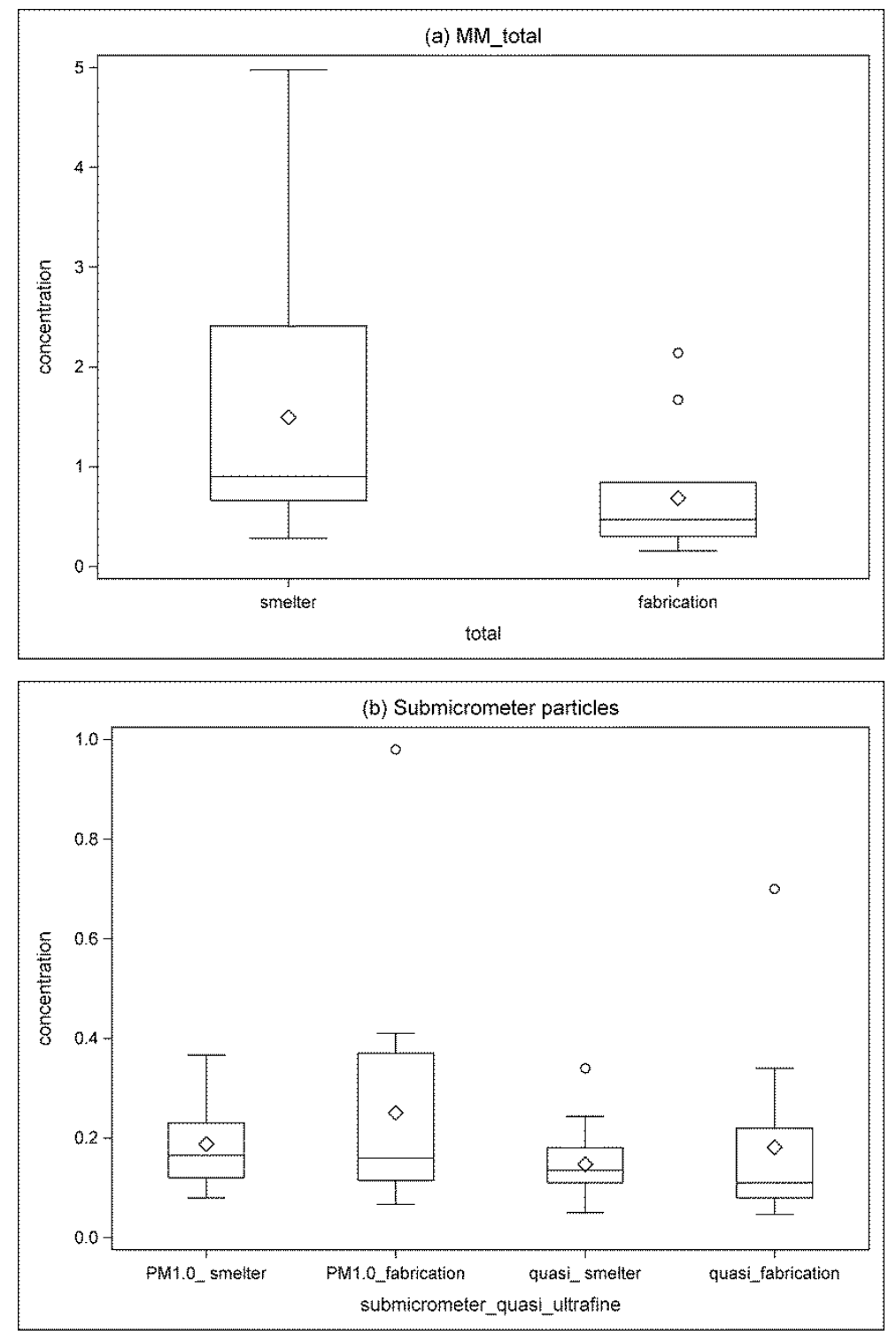

Figure 3.

\section{Discussion}

Our data indicated that the reproducibility of PMI and MiniMOUDI cascade impactors ranged from moderate to high. The precision for $\mathrm{PM}_{10}$ was slightly better than for $\mathrm{PM}_{3.2}$ (MiniMOUDI) or $\mathrm{PM}_{2.5}$ (PMI). The comparison between PMI and MiniMOUDI revealed that the precision for $\mathrm{PM}_{2.5}$ (PMI) was very similar to that for $\mathrm{PM}_{3.2}$ (MiniMOUDI). As to the validity, PMI_PM 2.5 was highly correlated with $\mathrm{MM}_{-} \mathrm{PM}_{2.5}(\mathrm{r}=0.97)$ and the slope of the regression line was 1.03. The agreement between PMI_PM 2.5 (measured) and MM_PM 2.5 (calculated) became not as strong as before, when two high $\mathrm{PM}_{2.5}$ concentration data points were not included, but they were still correlated $(\mathrm{r}=0.71)$. We do not consider those two measurements as outliers in our sampling data. The comparison between these two types of impactors may need more investigation for work settings with low PM concentrations or different particle size distributions. Total particle concentrations measured by PMI, MiniMOUDI and cassette did not agree well (not presented), which was not surprising, due to the effect of entry efficiency of these instruments. We did not observe the difference between PMI samples with first stage oiled versus not oiled, probably due to the property of the particles. Only limited numbers of oiled/non-oiled sample pairs were collected and most of them were collected at the fabrication processes where oil mist was the primary exposure. Both MiniMOUDI and PMI have been used to measure size selective particle air concentrations in environmental and occupational air pollution studies (Haynes et al., 2012; Hicks et al., 2012). However, neither the precision nor the validity of these impactors has been previously reported in published literature. Our 
findings contribute to the industrial hygiene knowledge of these instruments and can be used to help interpret similar measurement data in future studies.

We found that particle size distribution varied substantially in the production areas where area samples were collected. During aluminum manufacturing, workers are exposed to particles at each step from bauxite mining and refinery to smelting and metal materials fabrication. The central process of the aluminum smelting is electrolytic reduction, during which raw materials such as alumina, cryolite (Na3AlF6) and other salts are heated at high temperature $\left(980^{\circ} \mathrm{C}\right)$ in electrolytic cells (pots). Other two important processes in the aluminum smelters are anode and cathode making that involve mixing, heating and baking of anthracite, graphite, calcined petroleum coke, coal-tar pitch and other materials. The processes release air pollutants such as carbon monoxide, carbon dioxide, particulate and gaseous fluorides, sulfur dioxide, polycyclic aromatic hydrocarbons and particulates. Whereas fabrication involves using alloying, casting, rolling, extruding, forging, drawing and traditional machining operations to make aluminum alloys, tubes, plates, sheets, foil and other final specialty products. The primary exposures in fabrication are oil mist and metals. Therefore, total particulate concentrations have been traditionally observed to be higher in smelters than in fabrication facilities, which is consistent with what we observed in our personal samples (Noth et al., 2014) as well as area samples (Table 1).

However, depending on the processes from which particles are generated, the particle size may vary differently from the concentrations. In our study, we found that particle size distributions were distinctively different at the processes in the smelting versus the fabricating facilities. Particles were significantly larger in most areas sampled in the smelters than those in the fabrication units. Although particle air concentrations have been observed to be significantly higher in smelters than in fabrication units when total particle or $\mathrm{PM}_{2.5}$ were measured (Noth et al., 2014), MiniMOUDI data indicate that the fraction of $\mathrm{PM}_{10}$ (MiniMOUDI) that was $\mathrm{PM}_{1.0}$ or $\mathrm{PM}_{0.56}$ was significantly higher in the fabrication units than those in smelters and thus the sub-micrometer and quasi-ultrafine particle concentrations were actually similar in smelting and fabricating facilities. In a companion report, ischemic heart disease incidence was associated with recent $\mathrm{PM}_{2.5}$ exposure; the hazard ratio rose to 1.5 in both smelter and fabrication facilities, though the analysis yielded stronger evidence of exposure-response in fabrication compared to smelting facilities, personal exposure was almost an order of magnitude higher in smelters (Costello et al., 2014). Ultrafine particle exposure in smelters in the aluminum industry has been of concern as processes in the potrooms have been reported to generate substantial amounts of particles with elevated ultrafine particle number concentrations (Thomassen et al., 2006; Debia et al., 2012). However, processes in fabrication units can be potential sources of ultrafine particles as well. For example, ultrafine particles can be generated when metal working fluids are applied on hot metal surfaces during rolling and extrusion. To date, investigation of size specific particle exposure in the aluminum industry has focused on potrooms in smelters (Hoflich et al., 2005; Thomassen et al., 2006; Weinbruch et al., 2010; Debia et al., 2012; Skaugset et al., 2014). No particle size selective exposure data have been reported for the fabrication facilities. The findings of the current study suggest that fabrication facilities may have the same level of ultrafine particle exposure as smelters, despite the fact that particle concentrations in fabrication units have traditionally been considered to be lower based on measured total particle concentrations.

\section{Conclusions}

We examined the reproducibility of two types of cascade impactors, MiniMOUDI and PMI, based on co-located area samples collected in eight diverse aluminum production facilities. We found the precision for the impactors ranged from moderate to high, with most of CVs less than $30 \%$. Moreover, fine particles measured by PMI were found to be valid estimates of fine particle concentrations measured by MiniMOUDI. Considerable variations in particle size distribution and particle concentration were observed among production processes. Particle size and concentration varied substantially among departments in smelters, e.g., in the anode department from green anode to baked anode, but were similar in potrooms across facilities. In contrast, particle size and concentrations were much less variable in fabrication units. Particle size was significantly smaller in fabrications than in most areas of smelters. Although the area concentration of total particles was significantly higher in smelters than in fabrications, the area concentrations of sub-micrometer and quasi-ultrafine particles were similar, indicating exposure to ultrafine particles may be similar in smelters and fabrications.

Acknowledgements: We wish to acknowledge the contribution of the Alcoa industrial hygienists and employees who participated in the sampling campaigns at each facility. This work was supported by the Center for Disease Control and Prevention, National Institute of Occupational Safety and Health (5R01OH009939-02: Occupational Exposure to $\mathrm{PM}_{2.5}$ and Cardiovascular Disease), and by Alcoa, Inc.

Conflict of Interests: The authors declare no potential for conflict of interest. Dr. Cullen receives salary support 
from Alcoa, Inc. through contracts with Stanford University. Dr. Hammond had received compensation as a member of the scientific Occupational and Environmental Health Advisory Committee for Alcoa, Inc. She has also consulted for Alcoa, Inc. and received compensation. Christine Dixon-Ernst is an industrial hygienist for Alcoa, Inc.

NIA Data Sharing: As an alternative to providing a de-identified data set to the public domain, we allow access for the purpose of re-analyses or appropriate "follow-on" analyses by any qualified investigator willing to sign a contractual covenant with the host Institution limiting use of data to a specific agreed upon purpose and observing the same restrictions as are limited in our contract with Alcoa, such as 60-daymanuscript review for compliance purposes.

\section{References}

Costello, S., Brown, D. M., Noth, E. M., Cantley, L., Slade, M. D., Tessier-Sherman, B., Hammond, S. K., Eisen, E. A., \& Cullen, M. R. (2014). Incident ischemic heart disease and recent occupational exposure to particulate matter in an aluminum cohort. Journal of Exposure Science and Environmental Epidemiology, 24(1), 82-88. http://dx.doi.org/10.1038/jes.2013.47

Debia, M., Weichenthal, S., Tardif, R., \& Dufresne, A. (2012). Ultrafine Particle (UFP) Exposures in an Aluminium Smelter: Soderberg vs. Prebake Potrooms. Environment and Pollution, 1(1), 10.

Dockery, D. W., Pope, C. A., Xu, X. P., Spengler, J. D., Ware, J. H., Fay, M. E., Ferris, B. G., \& Speizer, F. E. (1993). An association between air-pollution and mortality in 6 United-States cities. New England Journal of Medicine, 329(24), 1753-1759. http://dx.doi.org/10.1056/NEJM199312093292401

Dominici, F., Peng, R. D., Bell, M. L., Pham, L., McDermott, A., Zeger, S. L., \& Samet, J. M. (2006). Fine particulate air pollution and hospital admission for cardiovascular and respiratory diseases. Jama-Journal of the American Medical Association, 295(10), 1127-1134. http://dx.doi.org/10.1001/jama.295.10.1127

Fang, S. C., Cavallari, J. M., Eisen, E. A., Chen, J. C., Mittleman, M. A., \& Christiani, D. C. (2009). Vascular Function, Inflammation, and Variations in Cardiac Autonomic Responses to Particulate Matter Among Welders. American Journal of Epidemiology, 169(7), 848-856. http://dx.doi.org/10.1093/aje/kwn405

Fang, S. C., Eisen, E. A., Cavallari, J. M., Mittleman, M. A., \& Christiani, D. C. (2008). Acute changes in vascular function among welders exposed to metal-rich particulate matter. Epidemiology, 19(2), 217-225. http://dx.doi.org/10.1097/EDE.0b013e31816334dc

Haynes, E. N., Ryan, P., Chen, A. M., Brown, D., Roda, S., Kuhnell, P., Wittberg, D., Terrell, M., \& Reponen, T. (2012). Assessment of personal exposure to manganese in children living near a ferromanganese refinery. Science of the Total Environment, 427, 19-25. http://dx.doi.org/10.1016/j.scitotenv.2012.03.037

Hicks, J. B., McCarthy, S. A., Mezei, G., \& Sayes, C. M. (2012). PM1 Particles at Coal- and Gas-Fired Power Plant Work Areas. Annals of Occupational Hygiene, 56(2), 182-193. http://dx.doi.org/10.1093/annhyg/mer085

Hoflich, B. L. W., Weinbruch, S., Theissmann, R., Gorzawski, H., Ebert, M., Ortner, H. M. ... Thomassen, Y. (2005). Characterization of individual aerosol particles in workroom air of aluminium smelter potrooms. Journal of Environmental Monitoring, 7(5). http://dx.doi.org/10.1039/b418275h

Laden, F., Neas, L. M., Dockery, D. W., \& Schwartz, J. (2000). Association of fine particulate matter from different sources with daily mortality in six US cities. Environmental Health Perspectives, 108(10), 941-947. http://dx.doi.org/10.1289/ehp.00108941

Miller, K. A., Siscovick, D. S., Sheppard, L., Shepherd, K., Sullivan, J. H., Anderson, G. L., \& Kaufman, J. D. (2007). Long-term exposure to air pollution and incidence of cardiovascular events in women. New England Journal of Medicine, 356(5), 447-458. http://dx.doi.org/10.1056/NEJMoa054409

NIOSH. (1994). Manual of Analytical Methods (4th ed.). Cincinnati, Ohio.

Noth, E. M., Dixon-Ernst, C., Liu, S., Cantley, L., Tessier-Sherman, B., Eisen, E. A., Cullen, M. R., \& Hammond, S. K. (2014). Development of a job-exposure matrix for exposure to total and fine particulate matter in the aluminum industry. Journal of Exposure Science and Environmental Epidemiology, 24(1), 89-99. http://dx.doi.org/10.1038/jes.2013.53

Ostro, B., Feng, W. Y., Broadwin, R., Green, S., \& Lipsett, M. (2007). The effects of components of fine particulate air pollution on mortality in California: Results from CALFINE. Environmental Health Perspectives, 115(1), 13-19. http://dx.doi.org/10.1289/ehp.9281 
Ostro, B., Roth, L., Malig, B., \& Marty, M. (2009). The Effects of Fine Particle Components on Respiratory Hospital Admissions in Children. Environmental Health Perspectives, 117(3), 475-480. http://dx.doi.org/10.1289/ehp.11848

Ostro, B. D., Feng, W. Y., Broadwin, R., Malig, B. J., Green, R. S., \& Lipsett, M. J. (2008). The impact of components of fine particulate matter on cardiovascular mortality in susceptible subpopulations. Occupational and Environmental Medicine, 65(11), 750-756. http://dx.doi.org/10.1136/oem.2007.036673

Peng, R. D., Chang, H. H., Bell, M. L., McDermott, A., Zeger, S. L., Samet, J. M., \& Dominici, F. (2008). Coarse particulate matter air pollution and hospital admissions for cardiovascular and respiratory diseases among medicare patients. Jama-Journal of the American Medical Association, 299(18), 2172-2179. http://dx.doi.org/10.1001/jama.299.18.2172

Pope, C. A., Ezzati, M., \& Dockery, D. W. (2009). Fine-Particulate Air Pollution and Life Expectancy in the United States. New England Journal of Medicine, 360(4), 376-386. http://dx.doi.org/10.1056/NEJMsa0805646

Simkhovich, B. Z., Kleinman, M. T., \& Kloner, R. A. (2008). Air pollution and cardiovascular injury. Journal of the American College of Cardiology, 52(9), 719-726. http://dx.doi.org/10.1016/j.jacc.2008.05.029

Skaugset, N. P., Berlinger, B., Radziuk, B., Torring, H., Synnes, O., \& Thomassen, Y. (2014). Visualisation and identification of peak exposure events in aluminium smelter pot rooms using hydrogen fluoride and aerosol real-time portable spectrometers. Environmental Science-Processes \& Impacts, 16(5), 1035-1040. http://dx.doi.org/10.1039/c3em00640a

Thomassen, Y., Koch, W., Dunkhorst, W., Ellingsen, D. G., Skaugset, N. P., Jordbekken, L., Drablos, P. A., \& Weinbruch, S. (2006). Ultrafine particles at workplaces of a primary aluminium smelter. Journal of Environmental Monitoring, 8(1), 127-133. http://dx.doi.org/10.1039/b514939h

Weinbruch, S., Benker, N., Koch, W., Ebert, M., Drablos, P. A., Skaugset, N. P., Ellingsen, D. G., \& Thomassen, Y. (2010). Hygroscopic properties of the workroom aerosol in aluminium smelter potrooms: a case for transport of HF and SO2 into the lower airways. Journal of Environmental Monitoring, 12(2), 448-454. http://dx.doi.org/10.1039/b919142a

\section{Copyrights}

Copyright for this article is retained by the author(s), with first publication rights granted to the journal.

This is an open-access article distributed under the terms and conditions of the Creative Commons Attribution license (http://creativecommons.org/licenses/by/3.0/). 